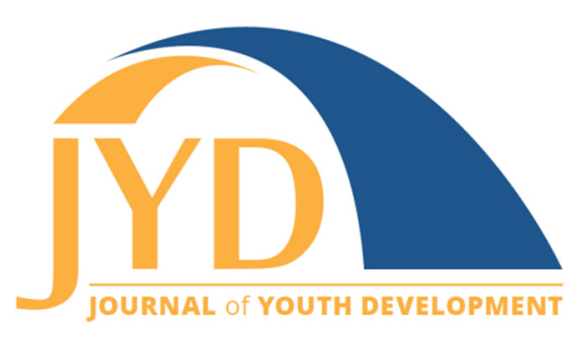

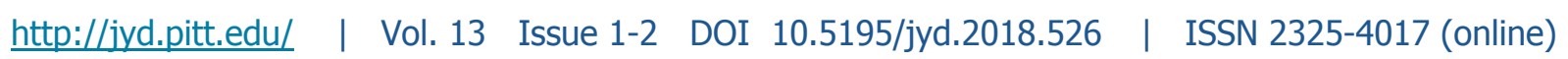

\title{
Camper Self-Concept Promotes Environmental Awareness: A Relationship Mediated by Social Inclusion
}

Luc S. Cousineau

University of Waterloo

luc.cousineau@uwaterloo.ca

Steven E. Mock

University of Waterloo

smock@uwaterloo.ca

Troy D. Glover

University of Waterloo

troy.glover@uwaterloo.ca

\begin{abstract}
Summer camps in Canada provide services to hundreds of thousands of youth each year, giving opportunities for growth and development. However, summer camps in Canada remain understudied. Using one phase of data from the Canadian Summer Camps Research Project (CSCRP), analysis was conducted on the effect of camper self-concept on their environmental awareness, mediated by perceived level of social inclusion. A relationship between camper self-concept and environmental awareness existed, and that relationship was enhanced when campers were socially included. These findings show preliminary connections between self-concept and environmental awareness in summer camps, and open opportunities for further research into personal and long-term effects of camp participation on environmental viewpoints, social group integration, and self-concept.
\end{abstract}

Key words: camp, environment, personal development, social inclusion, self-concept

\section{Introduction}

Summer camp experiences are significant in the development of many youth across North America, providing them with opportunities to learn and grow outside of school and home (Henderson, Whitaker, Bialeschki, Scanlin, \& Thurber, 2007; Paris, 2008). In the province of

\footnotetext{
(c)) EY New articles in this journal are licensed under a Creative Commons Attribution 4.0 License. This journal is published by the University Library System, University of Pittsburgh and is cosponsored by the University of Pittsburgh Press. The Journal of Youth Development is the official peer-reviewed publication of the National Association of Extension 4-H Agents and the National AfterSchool Association.
} 


\section{Self-Concept, Social Inclusion, and Environment}

Ontario, Canada, there are over 500 industry accredited camps, serving over 300,000 children annually (Ontario Camps Association, 2014). Although Ontario is the largest camp market in Canada, when compared with the United States, its numbers are dwarfed by the over 12,000 accredited overnight and day camps across the United States, serving over five million children in a $\$ 15$ billion dollar industry (American Camp Association, 2015). This market information situates summer camp as a research milieu with great potential, and although a significant body of research exists on summer camps in the United States, camp remains under-researched in the Canadian context.

The development of Canadian summer camps largely mirrors that of American summer camping, with initial development of short-term outdoor adventures throughout the late 1800s supported by various groups (e.g., YMCA, Tuxis Boys), followed by a surge of development in the first half of the $20^{\text {th }}$ century (Fine, 2005). Early Canadian camps, like their American counterparts, adopted the anti-modernist approach to development and the racial play-acting of "going Native" in names and traditions (Wall, 2005). Despite their similar developmental trajectories, camping traditions in Canada and the United States have occurred within distinct social and political contexts (Arnold \& Tigert, 1974; Baer, Grabb, \& Johnson, 1990, 1993). Therefore, although the findings of this study could apply to American summer camps and their programs, it is important to acknowledge this research was conducted with Canadian youth at Canadian camps. Few studies measuring camp outcomes for youth in Canada exist in the academic literature (Eagles \& Demare, 1999; Glover, Chapeskie, Mock, Mannel, \& Feldberg, 2011; Glover et al., 2013), and fewer still (Carruthers, 2013; Lichti, 2014) have done meaningful analysis of any baseline data collected by the aforementioned authors.

\section{Purpose}

The purpose of this paper is to extend the discussion and knowledge on summer camp outcomes for youth in Canada by exploring relationships between camper development measures from the Canadian Summer Camps Research Project, Phase 2 (CSCRP-2) (Glover et al., 2011; Glover et al., 2013). The CSCRP was a three-phase research project funded by the Canadian Camping Association, Social Sciences and Humanities Research Council Seed Grant Program, and the University of Waterloo, with the following goals: (a) to understand in what areas campers experience positive outcomes based on their camp experiences, and (b) to measure the degree of developmental change in these areas experienced over the course of a camp experience. Phase 2 of the CSCRP was a repeated measures survey that examined the perceived changes in camper attitudes and behaviors from the beginning to the end of their 


\section{Self-Concept, Social Inclusion, and Environment}

camping experience during one summer. In this phase of the CSCRP, surveys were completed by the staff directly responsible for the campers in question (staff between 18-25 years of age with direct supervisory roles over camper groups of 5-12 children), and were not self-reported by campers.

This paper hypothesizes that increased perceived camper self-concept will have a positive effect on perceived camper environmental awareness, and that this relationship will be mediated by the perceived social inclusion those same campers demonstrate. In other words, the better a camper feels about themselves, the more likely they are to exhibit positive environmental awareness, and that this relationship is enhanced by how socially included those campers are in their camping peer group.

\section{Literature Review}

A wide range of research has been conducted about the outcomes of summer camp experiences with youth in North America with the vast majority of this research conducted in the United States. Research on summer camp experiences has shown that participants develop positive self-image/self-concept (Hazelworth \& Wilson, 1990; Larson, 2007; Quinlan, Kolotkin, Fuemmeler, \& Costanzo, 2009; Thurber, Scanlin, Scheuler, \& Henderson, 2007), better socialization behaviors (Bialeschki, Henderson, \& James, 2007; Garst, Browne, \& Bialeschki, 2011; Glover et al., 2011; Henderson, Whitaker, et al., 2007), and personal values, which they continue to hold after their time at camp is over (Henderson, Bialeschki, et al., 2007; Paris, 2008). In addition, the effects of camp experiences on children 's emotional well-being, and parent involvement in children's lives have been explored (Garst et al., 2011; Henderson, Bialeschki et al., 2007; Henderson, Whitaker et al., 2007; Thurber \& Malinowski, 1999), and environmental awareness and education of campers has also received some attention (Dresner \& Gill, 1994; Kruse \& Card, 2004).

This wide range of experiential measurements notwithstanding, little work has been conducted on the effects that might exist through compounded or mediated relationships between these outcome variables (see: Carruthers, 2013; Lichti, 2014). Mediation, moderation, and other causal relationship measures help to better understand the larger social and developmental implications and outcomes of settings like summer camp, as they can illuminate some of the complex interactions that take place in these highly varied environments (Wu \& Zumbo, 2008). These types of measures give us a better understanding of how our actions, and the varied 
Self-Concept, Social Inclusion, and Environment

learning outcomes of summer camp programs, help campers develop and change as a result of camp experiences.

Socio-emotional well-being (self-confidence and personal development, or self-concept), appears to have lasting effects on children beyond initial experiences (Holden, Moncher, Schinke, \& Barker, 1990). When children feel more self-confident, they are better able to integrate into social groups, make friends, and develop social skills (Brown \& Lohr, 1987; Cast \& Burke, 2002). The development of self-concept and social skills they experience is a demonstration of Bandura's (1977) self-efficacy theory. This self-efficacy may allow campers to better engage with their peer groups, build stronger relationships at camp, and develop better social ties that result in building a stronger self-concept and feeling more included.

Where individuals feel more socially included with their peers, they are more likely to engage with group social norms, social activity structures, and group philosophies (Ellis \& Zarbatany, 2007; Kwon \& Lease, 2009; Salmivalli \& Voeten, 2004). The rules and expectations they might encounter at camp are a good example. Within the summer camp setting, group philosophies could include pro-environmental behavior developed through outdoor programming, and perceived connectedness to nature and others (Eagles \& Demare, 1999; Paris, 2008; Smith, 2006). In addition to camp's environmental values, norms and practices that encourage social inclusion are an important part of almost all camp programs (e.g. Brookman et al., 2003; Michalski, Mishna, Worthington, \& Cummings, 2003). Teaching social and environmental values together in summer camp programs is an example of Lehtonen's (2004) environmental-social co-evolutionary framework and is a psychologically valuable learning and development process (see also: Macnaghten \& Urry, 1998; Porter, 2006; van Jaarsveld, 1996).

Through the work of authors in outdoor adventure and education research, as well as environmental psychology (see: Bell, Greene, \& Fisher, 2001; Ewert, 1987, 1983; Gillett, Thomas, Skok, \& McLaughlin, 1991; Propst \& Koesler, 1998, among others), we see a link between the self and the environment, forming the theoretical foundation for measured connections between self-concept and levels of environmental awareness. Where both selfconcept and environmental awareness can be connected to social inclusion in a peer group, a theoretical link can be established where social inclusion might mediate the relationship between self-concept and environmental awareness.

Most work on Canadian summer camp experiences has focused on peripheral programming conducted at camp, including outdoor education and curriculum links (Eagles \& Demare, 1999; 


\section{Self-Concept, Social Inclusion, and Environment}

Henderson \& Potter, 2001), as well as camp-linked interventionist programming (e.g. Nicholas, Williams, \& MacLusky, 2009). The work of Glover and colleagues (2011; 2013) established baseline information about the experiences of summer camp attendees in a specifically Canadian context. Glover et al.'s CSCRP-2 (2011) showed statistically significant positive gains between arrival and departure from camp in five categories: social integration at camp, environmental awareness, self-confidence and personal development, emotional intelligence, and attitudes toward physical activity. This repeated measures data set can begin to provide insight into specific elements of camp experiences for Canadian youth.

With these theoretical connections established, this paper asks if the CSCRP-2 contains statistical evidence of the existence of a relationship between self-concept and environmental awareness in youth summer camping in Canada, and if so, is that relationship mediated by the level of perceived group social inclusion of campers? Using Glover et al.'s (2011) data, this paper tests links between self-concept at camp and increased environmental awareness, exploring social inclusion as a potential mechanism, in order to demonstrate interlinked outcomes from youth participation in summer camp programs.

\section{Methods}

Data from Glover et al.'s CSCRP-2 (2011) were used. The primary goal of the CSCRP-2 was to understand the outcome areas of participant campers during their time at Canadian day and overnight camps, and to measure the degree of change in these areas. The second phase of the CSCRP's three-phase project focused on the perceived effects, measured by staff with the most direct contact with campers (cabin staff or group leaders), of summer camp on campers. This effect was measured in five categories: social integration at camp, environmental awareness, self-confidence and personal development, emotional intelligence, and attitudes toward physical activity. These categories were identified in Phase 1 of the CSCRP through indepth interviews with 65 camp directors.

\section{Measures}

The CSCRP investigated change in camper behavior and experience over time. The second phase consisted of a survey instrument based on the five major areas of summer camp focus. The instrument for phase two was a 42-item survey subdivided into five categories: (a) social integration and citizenship, (b) environmental awareness, (c) self-confidence and personal development, (d) emotional intelligence, and (e) attitudes towards physical activity (for a 
Journal of Youth Development | http://jyd.pitt.edu/ | Vol. 13 Issue 1-2 DOI 10.5195/jyd.2018.526

Self-Concept, Social Inclusion, and Environment

complete list of scales and survey items used see Glover et al., 2011). Each item of the survey was measured using a 7-point scale ( 1 = very strongly disagree; 7 = very strongly agree).

In the analysis presented here, sub category scales were used. These sub-scales are either distinct portions of larger scales used in the research instrument (e.g., social integration subscale is one part of the social integration and citizenship scale), or complete scales from the research instrument (e.g., environmental awareness scale).

\section{Self-Confidence and Personal Development}

Assessment of self-confidence and personal development ( $\left.\mathrm{a}_{\mathrm{T} 1}=.87, \mathrm{a}_{\mathrm{T} 2}=.88\right)$ consisted of an eight-item measure drawing from distinct focal areas identified as development points by camp directors in Phase 1 of the CSCRP (sample item: "The camper appears to be confident in him/herself"). One item in the self-confidence and personal development scale was reversecoded for analysis. For this paper, the term self-concept is used in place of self-confidence and personal development for easier reading.

\section{Environmental Awareness}

Environmental Awareness ( $\mathrm{a}_{\mathrm{T} 1}=.89, \mathrm{a}_{\mathrm{T} 2}=.90$ ) was assessed using the complete, five item environmental awareness scale from the CSCRP survey (sample item: "This camper shows an awareness of his/her impact on the environment").

\section{Social Integration}

Assessment of social integration ( $a_{\mathrm{T} 1}=.82, \mathrm{a}_{\mathrm{T} 2}=.86$ ) used a four-item sub-scale from the social integration and citizenship measure developed for the CSCRP and were asked together as a sub-section of the survey (sample item: "The camper has friends at camp besides those in his/her counselor group").

\section{Emotional Intelligence and Attitudes towards Physical Activity}

Although the CSCRP measured perceived emotional intelligence and attitudes towards physical activity, those measures were not used in the analysis presented in this paper. Basic information about these measures is included here for reader information. 


\section{Self-Concept, Social Inclusion, and Environment}

Emotional intelligence was assessed using 10 items $(a=.89)$ related to a camper's awareness of his/her own emotions, the emotions of others, and the ability to demonstrate considerate interactions with peers (sample item: "This camper is sensitive to the feelings and emotions of others").

Physical activity attitudes were assessed through seven items $(a=.94)$, which reflected the degree that the camper had positive attitudes toward physical activity, sports, and games (sample item: "When given a choice this camper always chooses physical activities").

\section{Analysis}

Two linear regression models were constructed to examine the association between selfconcept and environmental awareness, and the possible mediating role of social integration in this relationship. Linear regression is an approach for modeling the relationship between a dependent variable and one or more explanatory (or independent) variables, allowing for a prediction of the outcomes of that relationship. The first model included demographic characteristics/control variables (e.g., age and sex), as well as the outcome variable (environmental awareness - Time 1 (T1)), and the initial mediating variable value (social inclusion T1). The second model introduced the social inclusion mediating variable at the time of camp departure (social inclusion - Time 2 (T2)).

Tests for mediation allow statistical analysis of the potential effect of a third variable as a mechanism acting on the relationships of existing variables; in this case how the change in social inclusion between T1 and T2 changed the relationship between self-concept and environmental awareness. The Hayes (2009) method of bootstrapping using the PROCESS macro for SPSS was used to test statistical significance between a main predictor variable and an outcome variable. Bootstrapping is a method of resampling and replacing data many times, measuring an indirect effect between variables, and a distribution of this indirect effect (Hayes, 2009). This distribution allows for the creation of a percentile-based confidence interval that avoids the need for the assumption of normal distribution (Hayes, 2009). This approach generates a more reliable outcome with a smaller margin for error in measuring the indirect effect of the mediator on the relationship between the dependent and independent variables. In this model self-concept was the independent variable, environmental awareness was the dependent variable, and social integration was the mediator. 


\section{Results}

The CSCRP-2 yielded measures of camper change over the duration of their stay at camp as perceived by the staff who directly supervised them (staff between 18 and 25 years of age with direct supervisory roles over campers). Data were collected on $n=1,288$ campers from 16 summer camps across Canada. Of the 16 camps, 13 were co-ed, two camps served exclusively female campers, and one camp served exclusively male campers. Camps were nearly evenly split between overnight camps (nine), and day camps (seven). Campers who were measured in this study attended a minimum 1-week camp session. Campers ranged in age from 3 to18 years (mean age $=10.44, \mathrm{SD}=3.05$ ). The survey was administered as repeated measures, i.e., within the first 48 hours of arrival at camp and within 48 hours of departure from camp. For the purposes of the current analysis, only campers aged seven or older were included, yielding a total number of campers of $n=1,095$ (mean age $=11.26$, $(\mathrm{SD}=2.39)$. This sample modification was done to best reflect the most common age groups accommodated in accredited Canadian summer camp programs ( 7 to 18 years), and reduce the scope of generalizations made in this paper.

Regression analysis showed that self-concept was significantly associated with environmental awareness (Table 1, Model 1), meaning that environmental awareness increased when participants showed positive gains in self-concept. With the addition of social inclusion and the longitudinal measures, regression demonstrated a significant association between the increase in social inclusion scores, self-concept, and environmental awareness scores (Table 1, Model 2). Table 1 shows the unstandardized regression coefficients for regression models examining associations of environmental awareness with self-concept and social inclusion. A significant indirect effect of self-concept on environmental awareness through social inclusion was found ( $b=.112 \mathrm{BCa} \mathrm{CI}[0.073,0.158]$ ), where $b$ is the indirect effect, using bias-corrected percentile acceleration ( $\mathrm{BCa})$, and $\mathrm{CI}$ is the confidence interval. These statistical findings indicate that the perceived social inclusion of campers had a statistically significant effect on the relationship between the self-concept and environmental awareness of campers. 
Table 1. Unstandardized Regression Coefficients for Regression Models Examining Associations of Environmental Awareness with Self-Concept and Social Inclusion.

\begin{tabular}{|l|l|l|l|l|l|}
\hline & \multicolumn{3}{|c|}{ Model 1 } & \multicolumn{2}{c|}{ Model 2} \\
\hline Independent variables & Coefficient & SE & Coefficient & SE \\
\hline Constant & .221 & .13 & .165 & .13 \\
\hline Age & $-.01 \dagger$ & .01 & $-.01 \dagger$ & $.01 \dagger$ \\
\hline Camp sex & .03 & .03 & $.01 \dagger$ & .03 \\
\hline Returning camper & .02 & .03 & .03 & .03 \\
\hline Wilderness setting & .06 & .03 & .04 & .03 \\
\hline Environmental awareness T1 & $.82 * *$ & .03 & $.81 * *$ & .03 \\
\hline Self-concept T1 & $-.34 * *$ & .04 & $-.28 * *$ & .04 \\
\hline Self-concept T2 & $.44 * *$ & .03 & $.33 * *$ & .04 \\
\hline Social inclusion T1 & -.03 & .02 & $-.08 *$ & .03 \\
\hline Social inclusion T2 & & & $.18 * *$ & .03 \\
\hline Adjusted R & & & .65 & & .66 \\
\hline
\end{tabular}

$n=1019$ (76 cases excluded due to missing data)

${ }^{*} p<.01, * * p<.001$

† Value was rounded up to .01 , but was below rounding threshold on calculation.

Social inclusion was associated with the link between self-concept and environmental awareness, and analyses were conducted to determine the degree to which the association between these two variables was accounted for by the mediator (Figure 1). The total effect ( $c$ ) of self-concept on environmental awareness was significant $(\beta=0.44, \mathrm{SE}=.03, p<.001)$ and compared to the total effect, the direct effect ( $c$ ) of self-concept on environmental awareness was somewhat reduced $(\beta=0.33, \mathrm{SE}=.04, p<.001)$. The model of the mediation pathway where the unstandardized regression coefficient $a$ path $(\beta=.62$, SE $=.03, p<.001)$ was statistically significant, as was the $b$ path $(\beta=.30, \mathrm{SE}=.02, p<.001)$. Table 2 shows the total, direct, and indirect effects with bootstrapping analysis for the association of environmental awareness with self-concept and social inclusion for summer camp participant youth. 
Figure 1. Association Between Self-Concept and Environmental Awareness Partially Mediated by Social Inclusion

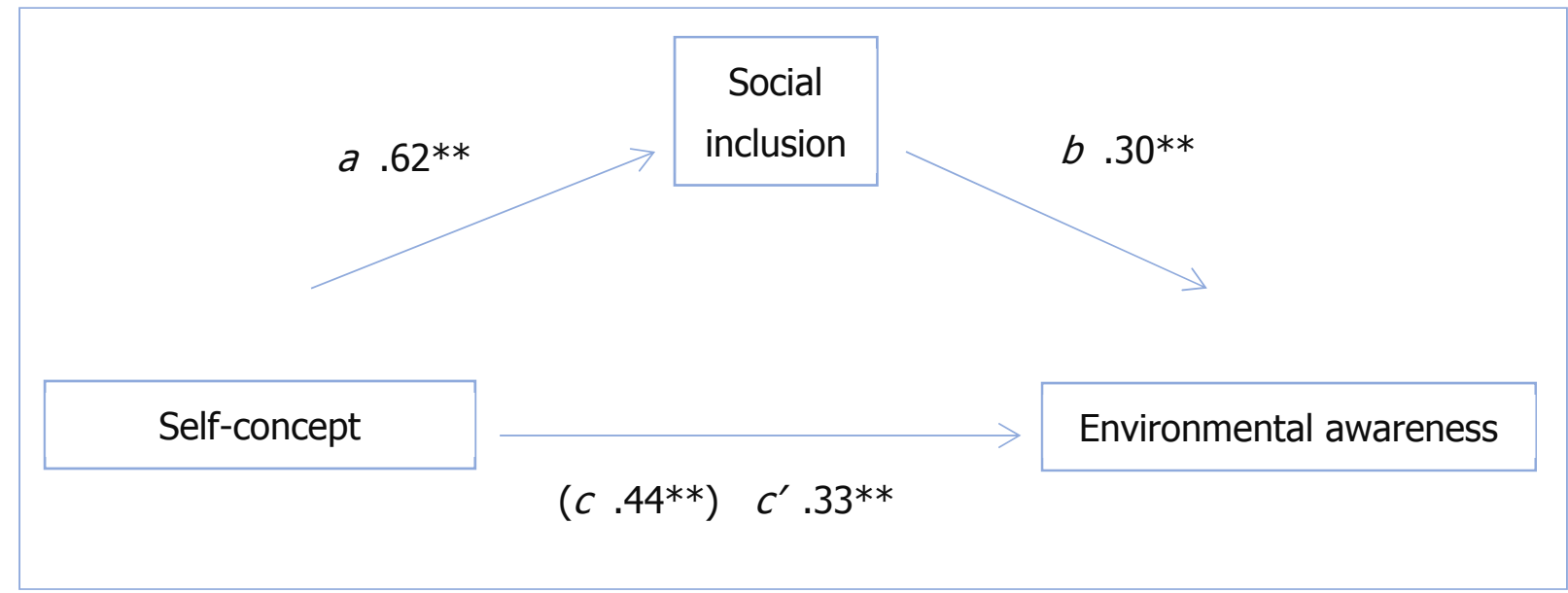

Note: Values in parentheses are standardized coefficients before the addition of social inclusion to the models. $* * p<.001, n=1019$

Table 2. Total Effects, Direct Effects, and Bootstrap Analysis of Indirect Effect for the Association of Environmental Awareness with Self-Concept Mediated by Social Inclusion

\begin{tabular}{|l|l|l|l|l|}
\hline \multicolumn{2}{|c|}{} & \multicolumn{2}{c|}{ Bootstrapping } \\
\hline \multicolumn{2}{|c|}{} & \multicolumn{2}{c|}{ 95\% CI } \\
\hline Total effect (c) & .440 & .031 & - & - \\
\hline Direct effect (c') & .328 & .035 & - & - \\
\hline Indirect effect $(a b)$ & .112 & .022 & .073 & .158 \\
\hline
\end{tabular}

\section{Discussion}

Campers measured during the CSCRP-2 study showed increases in environmental awareness associated with increased levels of self-concept after their stays at camp. Previous studies have shown lasting positive effects from increased positive self-concept in children (Holden et al., 1990), and work on summer camp experiences has shown that summer camps promote this type of development (Garst et al., 2011; Thurber et al., 2007). The work of the CSCRP (Glover 


\section{Self-Concept, Social Inclusion, and Environment}

et al., 2011) also demonstrated these gains in Canadian summer camps context, and further supports the assertion that attending summer camp was an asset in young people's development of self-concept and social skills. What is most important about these findings is how they connect with environmental awareness, given the importance of the outdoors, connections with nature, and environmental ethics in historical (Paris, 2008) and contemporary camp programming (Glover et al., 2011, Smith, 2006). Alone, the finding that self-concept is associated with environmental awareness is interesting but not particularly useful, until we can better understand the mechanism(s) linking these two concepts. This study shows that mechanism to be, at least in part, the work of social inclusion that is so important to camp programming.

Many summer camps maintain a mandate of social integration and friendship-making for campers (Mecke \& Hutchison, 2005; Thurber et al., 2007). Deliberate policies to develop social relationships at camp are already designed together with building camper self-concept, and the combined value of these approaches can yield additional benefits from the camp program, like better environmental awareness as demonstrated here. The mediated relationship discussed in this paper indicates that campers, through feeling better about themselves and making friends, are internalizing environmental norms and lessons at camp. Furthermore, it provides additional empirical evidence to Lehtonen's (2004) social-environmental model highlighting an important socio-psychological link going forward that can help to better educate children in a time of contentious discussion about climate change, climate science, and approaches to these environmental challenges.

The findings presented here should provide encouragement to camp managers to continue their important work in developing campers' self-concept, and their inclusion in peer and larger camp social groups, as they are likely to see benefits beyond the personal gains of campers and positive social gains for the camp community. As evidenced here, campers who feel more a part of camp are more likely to take on camp norms and philosophies. For environmental awareness in particular, as a foundational element of camp philosophy already important in the community ethics and norms at camp, this study shows promising evidence that gains can be made in multiple ways. When campers feel more a part of the social groups and camp peer community, they are more likely to accept and adopt those ethics and norms. For example, as I feel better about myself, the more likely and willing I am to make friends at camp. The more friends I make, the more I feel truly a part of the camp community. The more I feel a part of the camp community, the more I want to learn, live, and breathe my camp's philosophy-and not just about the environment. 
Individually, each of the measures discussed in this paper are important developmental factors for youth, and important areas where camps focus a great deal of time and energy in program and staff development. Training hours and dollars are spent to ensure that camp staff have sufficient environmental knowledge and ethics to maintain a camp's 'green' commitment. Staff are given extensive theoretical and practical training on how to encourage positive self-concept in campers, and how to help camps build good quality peer relationships. Far less energy is spent on exploring or explaining how these individual elements might work together, or how camp managers might encourage the development of one through the development of another.

The implications of demonstrating this type of relationship between important outcomes of camp programming for campers are significant. First and foremost, the relationship provides additional, complex support for the already robust development mandates that camps have for campers. Demonstrating compound positive effects of camp programming helps to support camping as an industry and a place for robust child development in the eyes of parents. These relationships between outcomes could also allow camp managers to apply a more complex pedagogy to their programs, where layered and stacked program outcomes are able to generate more significant gains for participants than individualized outcomes alone. There are also implications for the way that camp managers engage their direct staff managers, empowering them to understand the larger puzzle created by the individual program and developmental pieces of the camp program. Further, the results of this study indicate that one of the pathways to have campers internalize ethical standards and camp norms is through their peer groups and the social expectations created in those groups; teaching ethics and standards is simply not enough.

The first author notes that in his years directing camp in Ontario, these findings were things that he knew intuitively. The campers who were most invested in the peers they met at camp, and how camp made them feel on a personal level, were always the ones who were most thoroughly devoted to camp's larger goals and ethics. When he brought them on as staff, he knew he did not have to convince them of the value of these lessons; they understood that each way camper development was encouraged formed one piece of the larger puzzle of the benefits of camp for campers. In this paper we have tried to show that empirical links exist, grounded in statistical data, showing the positive gains campers make at camp, and that the complexity of the programming and planning that camp directors and managers do allows those positive gains to compound with one another and generate even stronger positive outcomes. 


\section{Limitations and further research}

Work in establishing robust data sets and subjecting those data sets to secondary analysis must continue, as this research (and previous research in this area) is not without limitations. In this study, camper survey responses were completed by the staff members who were directly supervising those campers each day throughout their stay. Although this process likely allowed for increased continuity in responses and increased repeated response rate (due to surveys forming part of work responsibilities), responses analyzed here are not camper voices, but those of camper-supervising staff, and thus are subject to respondent subjective interpretation of the experiences of others. However, those staff persons are also well positioned to observe significant numbers of actions and interactions over the course of camper stays and are likely able to detect patterns or changes that the individual would not immediately recognize, especially in younger campers. Also, the fact that staff are completing these surveys as part of their employment role may introduce a positivity bias into the data, since they likely desire to see positive outcomes for their campers, both as a measure of job performance and personal satisfaction. In addition, the data provided by the CSCRP has a fairly wide age distribution. Although some of this range was mitigated in this study by including only campers seven years of age and over, opportunity exists for more directed sampling in the future to have a better break-down of age-related outcomes in the areas studied here.

The CSCRP data sets provide significant avenues for additional research on summer camp experiences in youth. With relatively few studies having been conducted on this data to-date (see: Carruthers, 2013; Lichti, 2014), analysis within individual data sub-scales using control or filter data for comparisons, or inter-scale analysis like that presented here, present a myriad of opportunities that could be valuable at both the industry and academic levels.

\section{Acknowledgement}

This research was supported by the Social Sciences and Humanities Research Council of Canada.

\section{References}

American Camp Association. (2015). ACA facts and trends. Retrieved from http://www.acacamps.org/press-room/aca-facts-trends 
Journal of Youth Development | http://jyd.pitt.edu/ | Vol. 13 Issue 1-2 DOI 10.5195/jyd.2018.526

Self-Concept, Social Inclusion, and Environment

Arnold, S., \& Tigert, D. (1974). Canadians and Americans: A comparative analysis. International Journal of Comparative Sociology, 15(1-2), 68-83.

Baer, D., Grabb, E., \& Johnson, W. (1990). The values of Canadians and Americans: A critical analysis and reassessment. Social Forces, 68(3), 693-713.

Baer, D., Grabb, E., \& Johnson, W. (1993). National character, regional culture, and the values of Canadians and Americans. Canadian Review of Sociology/Revue Canadienne de Sociologie, 30(1), 13-36.

Bandura, A. (1977). Self-efficacy: Toward a unifying theory of behavioral change. Psychological Review, 84(2), 191-215. doi: 10.1037/0033-295X.84.2.191

Bell, P. A., Greene, T. C., Fisher, J. D., \& Baum, A. S. (2001). Environmental Psychology. Mahwah, NJ: Lawrence Erlbaum.

Bialeschki, M. D., Henderson, K. A., \& James, P. A. (2007). Camp experiences and developmental outcomes for youth. Child and Adolescent Psychiatric Clinics of North America, 16(4), 769-788.

Brookman, L., Boettcher, M., Klein, E., Openden, D., Koegel, R. L., \& Koegel, L. K. (2003). Facilitating social interactions in a community summer camp setting for children with autism. Journal of Positive Behavior Interventions, 5(4), 249-252.

Brown, B. B., \& Lohr, M. J. (1987). Peer-group affiliation and adolescent self-esteem: An integration of ego-identity and symbolic-interaction theories. Journal of Personality and Social Psychology, 52(1), 47-55. doi: 10.1037/0022-3514.52.1.47

Carruthers, A. L. (2013). Emotional and social developmental benefits of summer camp for children: Examining the relationship between social capital and emotional intelligence. (Unpublished master's thesis). University of Waterloo, Waterloo, ON. Available at uwspace.uwaterloo.ca/bitstream/handle/10012/7629/Carruthers_Amanda.pdf

Cast, A. D., \& Burke, P. J. (2002). A theory of self-esteem. Social Forces, 80(3), 1041-1068. doi:10.1353/sof.2002.0003

Dresner, M., \& Gill, M. (1994). Environmental education at summer nature camp. The Journal of Environmental Education, 25(3), 35-41.

Eagles, P. F. J., \& Demare, R. (1999). Factors influencing children's environmental attitudes. The Journal of Environmental Education, 30(4), 33-37. doi:10.1080/00958969909601882

Ellis, W. E., \& Zarbatany, L. (2007). Peer group status as a moderator of group influence on children's deviant, aggressive, and prosocial behavior. Child Development, 78(4), 1240-1254. doi:10.1111/j.1467-8624.2007.01063.x

Ewert, A. W. (1983). Outdoor adventure and self-concept: A research analysis. Eugene: University of Oregon

Ewert, A. (1987). Research in outdoor adventure: Overview and analysis. Bradford Papers Annual, 2, 1528. 
Journal of Youth Development | http://jyd.pitt.edu/ | Vol. 13 Issue 1-2 DOI 10.5195/jyd.2018.526

Self-Concept, Social Inclusion, and Environment

Fine, S. (2005). Contextual learning within the residential outdoor experience: a case study of a summer camp community in Ontario. (Unpublished PhD Dissertation). University of Toronto. Toronto, ON. Retrieved from http://ccamping.org/wpcontent/uploads/2012/11/Fine_Stephen_2005_Contextual_Learning_within_the_Resident.pdf

Garst, B. A., Browne, L. P., \& Bialeschki, M. D. (2011). Youth development and the camp experience. New Directions for Youth Development, 2011(130), 73-87. 10.1002/yd.398

Gillett, D. P., Thomas, G. P., Skok, R. L., \& McLaughlin, T. (1991). The effects of wilderness camping and hiking on the self-concept and the environmental attitudes and knowledge of twelfth graders. The Journal of Environmental Education, 22(3), 34-44.

Glover, T. D., Chapeskie, A., Mock, S., Mannel, R., \& Feldberg, H. (2011). The Canadian summer camp research project: examining the outcomes of the Canadian summer camp experience. Waterloo, ON: University of Waterloo. Retrieved from http://ccamping.org/wpcontent/uploads/2012/11/CSCRP-Report-reduced.pdf

Glover, T. D., Graham, T., Mock, S., Mannel, R., Carruthers, A. L., \& Chapeskie, A. (2013). Canadian Summer Camp Research Project - phase 3: Parent perception of changes in children after returning home from camp. Waterloo, ON: University of Waterloo. Retrieved from http://ccamping.org/wp-content/uploads/2013/07/CSCRP-Phase-3-Final-Report.pdf

Hayes, A. F. (2009). Beyond Baron and Kenny: Statistical mediation analysis in the new millennium. Communication Monographs, 76(4), 408-420. doi: 10.1080/03637750903310360

Hazelworth, M. S., \& Wilson, B. E. (1990). The effects of an outdoor adventure camp experience on selfconcept. The Journal of Environmental Education, 21(4), 33-37.

Henderson, B., \& Potter, T. G. (2001). Outdoor adventure education in Canada: Seeking the country way back in. Canadian Journal of Environmental Education, 6(1), 225-242.

Henderson, K. A., Bialeschki, M. D., Scanlin, M. M., Thurber, C., Whitaker, L. S., \& Marsh, P. E. (2007). Components of camp experiences for positive youth development. Journal of Youth Development, $1(3), 1-12$.

Henderson, K. A., Whitaker, L., Bialeschki, M. D., Scanlin, M., \& Thurber, C. (2007). Summer camp experiences: Parental perceptions of youth development outcomes. Journal of Family Issues, 28(8), 987-1007. doi: 10.1177/0192513X07301428

Holden, G., Moncher, M. S., Schinke, S. P., \& Barker, K. M. (1990). Self-efficacy of children and adolescents: a meta-analysis. Psychological Reports, 66(3), 1044-1046. doi: 10.2466/pr0.1990.66.3.1044

Kruse, C. K., \& Card, J. A. (2004). Effects of a conservation education camp program on campers' selfreported knowledge, attitude, and behavior. The Journal of Environmental Education, 35(4), 3345. doi: 10.3200/JOEE.35.4.33-45 
Journal of Youth Development | http://jyd.pitt.edu/ | Vol. 13 Issue 1-2 DOI 10.5195/jyd.2018.526

Self-Concept, Social Inclusion, and Environment

Kwon, K., \& Lease, A. (2009). Children's social identification with a friendship group: A moderating effect on intent to conform to norms. Small Group Research, 40(6), 694-719. doi: $10.1177 / 1046496409346578$

Larson, B. A. (2007). Adventure camp programs, self-concept, and their effects on behavioral problem adolescents. Journal of Experiential Education, 29(3), 313-330.

Lichti, R. (2014). Examining Gender and Age as Predictors of Personal Development in a Summer Camp Setting as Mediated by Social Capital and Social Support . (Unpublished masters thesis). University of Waterloo, Waterloo, ON.

Macnaghten, P., \& Urry, J. (1998). Contested Natures. Thousand Oaks, California: Sage.

Mecke, T., \& Hutchison, P. (2005, May). A qualitative study of the inclusion process at a residential summer camp [Abstract]. Abstracts of Papers Presented at the Eleventh Canadian Congress on Leisure Research, Nanaimo, BC.

Michalski, J. H., Mishna, F., Worthington, C., \& Cummings, R. (2003). A multi-method impact evaluation of a therapeutic summer camp program. Child and Adolescent Social Work Journal, 20(1), 53-76.

Nicholas, D. B., Williams, M., \& MacLusky, I. B. (2009). Evaluating group work within a summer camp intervention for children and adolescents with asthma. Social Work with Groups, 32(3), 209-221.

Ontario Camps Association. (2014). What OCA offers. Retrieved from http://www.ontariocampsassociation.ca/join-oca/what-oca-offers/

Paris, L. (2008). Children's nature: The rise of the American summer camp. New York: NYU Press.

Porter, T. (2006). Coevolution as a research framework for organizations and the natural environment. Organization \& Environment, 19(4), 479-504. doi: 10.1177/1086026606294958

Propst, D. B., \& Koesler, R. A. (1998). Bandura goes outdoors: Role of self-efficacy in the outdoor leadership development process. Leisure Sciences, 20(4), 319-344.

Quinlan, N. P., Kolotkin, R. L., Fuemmeler, B. F., \& Costanzo, P. R. (2009). Psychosocial outcomes in a weight loss camp for overweight youth. International Journal of Pediatric Obesity, 4(3), 134-142.

Salmivalli, C., \& Voeten, M. (2004). Connections between attitudes, group norms, and behaviour in bullying situations. International Journal of Behavioral Development, 28(3), 246-258. doi: $10.1080 / 01650250344000488$

Smith, M. B. (2006). 'The ego ideal of the good camper' and the nature of summer camp. Environmental History, 11(1), 70-101. Retrieved from http://www.jstor.org/stable/3985739.

Thurber, C., \& Malinowski, J. (1999). Summer camp as a therapeutic landscape. In A. Williams (Ed.), Therapeutic landscapes: The dynamic between place and wellness (pp. 53-70). Lanham, MD: University Press of America.

Thurber, C., Scanlin, M. M., Scheuler, L., \& Henderson, K. A. (2007). Youth development outcomes of the camp experience: Evidence for multidimensional growth. Journal of Youth and Adolescence, 36(3), 241-254. 10.1007/s10964-006-9142-6 
Journal of Youth Development | http://jyd.pitt.edu/ | Vol. 13 Issue 1-2 DOI 10.5195/jyd.2018.526

Self-Concept, Social Inclusion, and Environment

van Jaarsveld, A. S. (1996). Towards a co-evolutionary framework for implementing sustainable development. International Journal for Sustainable Development and World Ecology, 3, 15-37.

Wall, S. (2005). Totem poles, teepees, and token traditions: 'Playing Indian' at Ontario summer camps, 1920-1955. The Canadian Historical Review, 86(3), 513-544.

Wu, A. D., \& Zumbo, B. D. (2008). Understanding and using mediators and moderators. Social Indicators Research, 87(3), 367-392. 10.1007/s11205-007-9143-1 